\title{
Highly Efficient and Selective Enrichment of Phosphopeptides Using Porous Anodic Alumina Membrane for MALDI-TOF MS Analysis
}

\author{
Yuebo Wang, ${ }^{\mathrm{a}, \mathrm{b}}$ Wei Chen, ${ }^{\mathrm{a}}$ Jianshuang $\mathrm{Wu}^{\text {a }}$ Yinlong Guo, \\ and Xinghua Xia ${ }^{\mathrm{a}}$ \\ ${ }^{a}$ Key Laboratory of Analytical Chemistry for Life Sciences, School of Chemistry and Chemical Engineering, \\ Nanjing University, Nanjing, China \\ b Shanghai Mass Spectrometry Center, Shanghai Institute of Organic Chemistry, Chinese Academy \\ of Science, Shanghai, China
}

\begin{abstract}
Because of its good biocompatibility, high surface-to-volume ratio, and distinct surface electrical properties, porous anodic alumina (PAA) membrane has been used to selectively enrich phosphopeptides from a mixture of synthetic peptides and tryptic digest product of $\beta$-casein by a direct MALDI-TOF MS analysis. As we reported previously, PAA membrane has strong incorporation ability to the phosphate anion. Herein, we describe the application of PAA membrane as a selective sampling absorbent for phosphopeptides. The PAA membrane could enrich phosphopeptides with high efficiency and selectivity; for example, the tryptic digest product of $\beta$-casein at a concentration as low as $4 \times 10^{-9} \mathrm{M}$ can be satisfactorily detected. Compared to that from the nonenriching peptide mixture, the MS signal of the phosphorylated peptides enriched by the PAA membrane is remarkably improved. In addition, acidic peptides have insignificant influence on the enriching process. Results show that the adsorption of phosphate anions on the PAA membrane plays a determining role in achieving highly selective enriching capacity toward phosphopeptides. The feasibility of PAA membranes as specific absorbents for phosphopeptides is also demonstrated. (J Am Soc Mass Spectrom 2007, 18, 1387-1395) @ 2007 American Society for Mass Spectrometry
\end{abstract}

$\mathrm{P}$ hosphorylation-the most important posttranslational modification of proteins-plays an important role in controlling many cellular processes in signal transduction, gene expression, cell growth, division, and apoptosis [1-3]. About $25-30 \%$ of the proteins in eukaryotic cells are estimated to be phosphorylated at a certain content in the life cycle. Therefore, characterization of the phosphorylation is an important issue in proteomic analysis [4]. Numerous methods such as radioactive ${ }^{32} \mathrm{P}$-labeling and detection [5], immunological methods [6], and Edman degradation [7] have been developed [8,9], although these techniques are relatively time consuming and laborious.

Recently, mass spectrometry (MS)-based methods have proved to be powerful and preferred approaches for the analysis of phosphorylation because of the higher sensitivity, selectivity, and speed than those of most biochemical techniques [10]. However, the electronegativity of the phosphate groups in phosphopeptides

Address reprint requests to Dr. Yinlong Guo, Shanghai Mass Spectrometry Center, Shanghai Institute of Organic Chemistry, Chinese Academy of Science, Shanghai 200032, China. E-mail: ylguo@mail.sioc.ac.cn and also to Prof. Xinghwa Xia, Key Laboratory of Analytical Chemistry for Life Science, Department of Chemistry, Nanjing University, Nanjing 210093, People's Republic of China. E-mail: xhxia@nju.edu.cn usually reduces the ionization efficiency during positive MS analysis [11]. In addition, phosphorylation is often substoichiometric. The presence of many nonphosphorylated peptides severely suppresses the ionization of phosphopeptides $[12,13]$. Therefore, separation and enrichment of phosphorylated peptides from unphosphorylated ones are highly desirable [14-16]. Several strategies have been developed to enrich the phosphorylated peptides or phosphoproteins before analysis, such as immunoprecipitation using phosphoprotein-specific antibodies $[17,18]$, immobilized metal affinity chromatography (IMAC) [19-21], and specific chemical modification strategies targeted for phosphorylated amino acids [22-24]. Among them, the most widely used method is IMAC. In this technique, phosphopeptides are selectively bound to the metal ions of $\mathrm{Fe}(\mathrm{III})$ or $\mathrm{Ga}$ (III) because of their affinity toward the phosphate moiety. Subsequently, the phosphopeptides are released using high $\mathrm{pH}$ or phosphate buffer for MS analysis. The main limitation of this approach is the background from unphosphorylated peptides (typically acidic in nature) that have affinity for the metal ions of $\mathrm{Fe}(\mathrm{III})$ or $\mathrm{Ga}(\mathrm{III})$. Alternatively, some metal oxides such as titanium dioxide has been applied to selectively concentrate phosphopeptides from complex samples 
[25-27]. The utility of zirconium dioxide microtips for phosphopeptide isolation before mass spectrometric analysis has also been demonstrated [28]. The metal hydroxide $\mathrm{Al}(\mathrm{OH})_{3}$, for phosphopeptide and phosphoprotein bindings, has also proved to be effective and more selective than commercial phosphoproteinenrichment kits [29].

Porous anodic alumina (PAA) membrane is a kind of self-ordered nanochannel aluminum oxide material formed by anodization of aluminum in appropriate multiprotic acid solutions. The structure of anodic porous alumina is described as a packed array of columnar hexagonal cells with central, cylindrical uniformly sized cavities ranging from 4 to $200 \mathrm{~nm}$ in diameter, pore density as high as $10^{8}$ to $10^{11}$ pores $/ \mathrm{cm}^{2}$, and film thickness varying from 0.1 to $300 \mu \mathrm{m}$ [30-32]. The dimension and the interval of the pores are controllable by varying the anodization voltage or using specific electrolyte of phosphoric acid [33], sulfuric acid [34], or oxalic acid [35]. This enables the PAA membrane to be used in fabricating nanometer-sized tubes, rods, and wires of various materials with a great flexibility [3639]. In addition, PAA has a good biocompatibility toward proteins by supramolecular interactions [40]. We have made use of the biocompatibility of the PAA to adsorb proteins. This approach allows a washing step for the removal of salts and buffer components from protein samples to enhance the MS spectral quality [41].

Recently, we found that the PAA membrane has strong incorporation ability toward phosphate anions [42]. Herein, we describe the application of PAA membrane as a selective sampling absorbent for the analysis of phosphopeptides. The free-standing PAA membranes anodized from solution of phosphoric acid or oxalic acid were synthesized using the method we reported previously [32]. The specifically adsorbed phosphopeptides were identified by a direct matrixassisted laser desorption/ionization time-of-flight mass spectroscopy (MALDI-TOF MS) analysis. Compared to that from the nonenriching peptide mixture, the MS signal of the phosphorylated peptides enriched by the PAA membrane is remarkably improved. The feasibility of PAA membranes as specific absorbents toward phosphopeptides is also demonstrated and the selective enrichment mechanism of the PAA toward phosphopeptides is discussed.

\section{Experimental}

\section{Materials}

The preparation method of PAA membranes was described in detail in our previous work [32]. ${ }^{\circ}$ The ${ }^{\circ}$ peptides TRDIYETDYYRK $(\mathrm{MW}=1622.73)$ and TRDIYpETDYYRK $(M W=1702.71)$ were obtained from Sangon Biotechnology Co., Ltd. (Shanghai, China) and used without further purification. The synthetic peptides dissolved in water and acetonitrile $(7: 3, \mathrm{vol} / \mathrm{vol})$ were mixed to a solution of $2 \times 10^{-8} \mathrm{~mol} / \mathrm{L}$. For the enriching experi- ments, the PAA membranes were cleaved into small pieces and immersed in $200 \mu \mathrm{L}$ of the above mixture for phosphopeptide adsorption. For comparison, direct deposition of the synthetic peptides mixture without enrichment to a PAA target was also performed. Solutions of both $\beta$-casein and trypsin (both from Sigma, St. Louis, $\mathrm{MO}$, USA) were prepared in aqueous ammonium bicarbonate $(30 \mathrm{mM}, \mathrm{pH} 8.2)$. $\beta$-Casein $(1 \mathrm{mg} / \mathrm{mL})$ and trypsin $(1 \mathrm{mg} / \mathrm{mL})$, at a weight ratio of 50:1, were incubated at $37^{\circ} \mathrm{C}$ for $15 \mathrm{~h}$ to produce a proteolytic digest for MALDITOF MS analysis, after which $10 \mu \mathrm{L}$ of $1 \mathrm{mg} / \mathrm{mL}$ tryptic $\beta$-casein digest was added to a $200 \mu \mathrm{L}$ mixture of water and acetonitrile (7:3, vol/vol). The PAA membrane was cleaved into small pieces and immersed in $200 \mu \mathrm{L}$ of the above mixture, then equilibrated for $6 \mathrm{~h}$ at $37^{\circ} \mathrm{C}$. After rinsing three times with $20 \mu \mathrm{L}$ water, the PAA pieces was again immersed in $200 \mu \mathrm{L}$ of a mixture of water and acetonitrile for $20 \mathrm{~min}$ to reduce the nonspecific adsorption. After adding the matrix and drying at room temperature, the PAA piece was affixed to a stainless steel target probe (MALDI target) using $2.0 \mu \mathrm{L}$ of polyurethane adhesive solution (NIPPOLLAN-DC 205, Nippon Polyurethane Industry Co., Ltd., Tokyo, Japan). For comparison, direct deposition of the tryptic $\beta$-casein digest mixture without enrichment to a PAA target was also performed.

The saturated solution of $\alpha$-cyano-4-hydroxycinnamic acid (Sigma) matrix was prepared in a mixture of water/acetonitrile (50:50, vol/vol) containing $0.1 \%$ TFA (Tedia, Fairfield, OH, USA). The DHB matrix (Sigma) was prepared by dissolving $20 \mathrm{mg}$ of 2,5-dihydroxybenzoic acid in $1 \mathrm{~mL}$ of water/acetonitrile (50:50, vol/vol) containing $1 \%$ phosphoric acid.

\section{Instrumentation}

MALDI-TOF MS analyses were performed using delayed extraction in positive-ion mode on a TOF mass spectrometer (Voyager-DE STR, Applied Biosystems, Framingham, MA, USA) using an accelerating potential of $20 \mathrm{kV}$. Spectra were obtained using a nitrogen laser $(337 \mathrm{~nm})$ adjusted to slightly above threshold. The spectra presented herein generally represent the sum of 200 laser shots. All spectra were recorded in the positive reflective mode using external calibration. In the post source decay (PSD) experiment, the precursor ions (proton adducts) were isolated using a timed ion selector. Each PSD mass spectrum was recorded in 11 segments under computer control. In all, 200 laser shots were accumulated per segment and all segments were switched together to form one MALDI-TOF PSD mass spectrum.

\section{Results and Discussion}

\section{Selective Enrichment of Phosphopeptides Using PAA Membrane Prepared in Phosphoric Acid}

Figure $^{\circ} 1^{\circ}$ shows $^{\circ}$ the ${ }^{\circ} \mathrm{SEM}^{\circ}$ microphotograph ${ }^{\circ}$ of ${ }^{\circ}$ an $^{\circ}$ ordered PAA film consisting of a hexagonal close-packed array of about 200-nm-diameter channels formed by the 
two-step anodization process with anodizing voltage of $120^{\circ} \mathrm{V}^{\circ}$ in $^{\circ} 0.2^{\circ} \mathrm{M}^{\circ}$ phosphoric ${ }^{\circ}$ acid $^{\circ}$ for ${ }^{\circ} 4^{\circ} \mathrm{h}^{\circ}[32]^{\circ} .^{\circ}$ The ${ }^{\circ}$ pore size of the PAA membrane is uniform and the interval of the pores is almost equal.

The effectiveness of the selective sampling technique using PAA in enriching the phosphopeptides was first evaluated using a mixture of the synthetic peptides TRDIYETDYYRK (MW $=1622.73)$ and TRDIYpET$\operatorname{DYYRK}^{\circ}\left(\mathrm{MW}^{\circ}={ }^{\circ} 1702.71\right){ }^{\circ}$ As ${ }^{\circ}$ shown ${ }^{\circ}{ }^{\circ}{ }^{\circ}$ Figure $2 \mathrm{a}$, only ${ }^{\circ} \mathrm{a}$ weak signal of phosphopeptide $(\mathrm{m} / \mathrm{z}$ 1703) was observed without any enrichment process. Apparently the signal of the phosphopeptide is severely suppressed in the mass spectrum. When the sample was enriched using the PAA membrane, the MS signal of phosphopeptide $(\mathrm{m} / \mathrm{z}$ 1703) became prominent, whereas almost no unphosphorylated peptide $(\mathrm{m} / \mathrm{z} 1623)$ appeared (Figure $\left.{ }^{\circ} 2 \mathrm{~b}\right) .{ }^{\circ}$ The $^{\circ}{ }^{\circ}$ calculated ${ }^{\circ}$ signal-to-noise $(\mathrm{S} / \mathrm{N})^{\circ}$ ratios for the phosphopeptide $(\mathrm{m} / \mathrm{z}$ 1703) are 257.9 for the nonenrichment process and 1924.6 for enrichment by the PAA membrane. The results indicate that the PAA membrane could specifically adsorb and enrich the phosphorylated peptide from the mixture of synthetic peptides.

Bovine $\beta$-casein bearing five phosphorylated serine residues has been extensively investigated as a model phosphoprotein. Its tryptic digest product was used to examine the enriching capacity of the PAA membrane made ${ }^{\circ}{ }^{\circ}$ phosphate $^{\circ}$ acid $^{\circ}$ tow ard $^{\circ}$ phosphopeptides. $^{\circ}$ Figure ${ }^{\circ} 3 a^{\circ}{ }^{\circ}$ displays ${ }^{\circ}$ the ${ }^{\circ} \mathrm{MALDI}^{\circ}$ mass $^{\circ}$ spectra $^{\circ}$ of ${ }^{\circ}$ the $e^{\circ}$ tryptic digest product of $\beta$-casein directly deposited onto a PAA target. Without any enrichment process, only a weak signal of phosphopeptide $(\mathrm{m} / \mathrm{z}$ 2062) was observed, indicating that the signals of the phosphopeptides are severely suppressed in the positive mass spectra. When the samples were enriched with the PAA membrane, the MS signal of phosphopeptide $(\mathrm{m} / \mathrm{z} 2062)$ became ${ }^{\circ}$ prominent $^{\circ}\left(\right.$ Figure $\left.^{\circ} 3 \mathrm{~b}\right){ }^{\circ}{ }^{\circ}$ whereas ${ }^{\circ}$ the ${ }^{\circ}$ other ${ }^{\circ}$ signals ${ }^{\circ}$ observed ${ }^{\circ}{ }^{\circ}{ }^{\circ}$ Figure $^{\circ} 3 \mathrm{a}^{\circ}$ disappeared. ${ }^{\circ}$ The ${ }^{\circ} \mathrm{MS}^{\circ}$ signal at $m / z 1968$ could be assigned to the dephosphorylated fragment of the phosphopeptide by loss of $\mathrm{H}_{3} \mathrm{PO}_{4}$. The

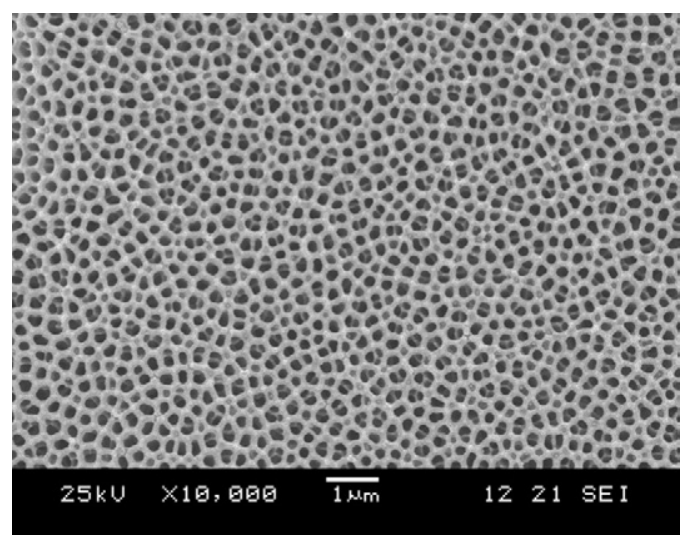

Figure 1. SEM microphotograph of the top surface of a highly ordered PAA membrane with pore about $200 \mathrm{~nm}$ in diameter formed by the two-step anodization process with anodizing voltage of $120 \mathrm{~V}$ in $0.2 \mathrm{M}$ phosphoric acid solution for $4 \mathrm{~h}$.

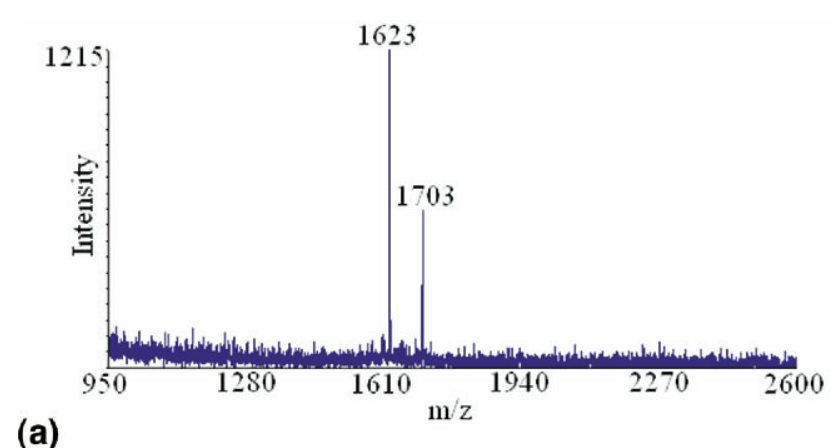

(a)

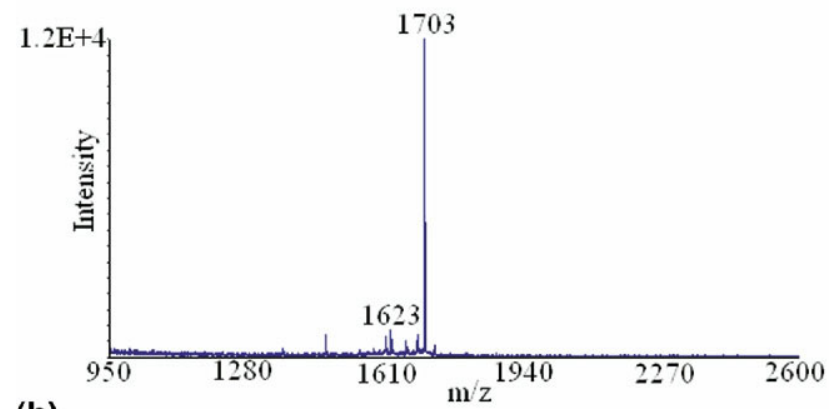

(b)

Figure 2. MALDI mass spectra of the synthetic peptides mixture $\left(2 \times 10^{-8} \mathrm{M}\right)$ deposited on the PAA target (a) and enriched by the PAA membrane for $6 \mathrm{~h}(\mathrm{~b})$. Saturated CHCA in a mixture of 50:50 water/acetonitrile (vol:vol) with $0.1 \%$ trifluoroacetic acid was used as matrix for MALDI-TOF MS analysis. PAA membranes were obtained by constant-voltage anodization at $120 \mathrm{~V}$ in $0.2 \mathrm{M}$ phosphate acid.

difference of $94 \mathrm{Da}$ instead of the normal $98 \mathrm{Da}$ between $\mathrm{m} / \mathrm{z} 2062$ and $\mathrm{m} / \mathrm{z} 1968$ could be attributable to the metastable loss of $\mathrm{H}_{3} \mathrm{PO}_{4}$ from the parent ions, which could be verified by the broadening and low resolution of $^{\circ}$ the ${ }^{\circ}$ signal $^{\circ}$ of $^{\circ} \mathrm{m} / \mathrm{z} 1968^{\circ}\left[16,{ }^{\circ} 43\right] . .^{\circ}$ Compared $^{\circ}$ to $^{\circ}$ the results ${ }^{\circ}$ in $^{\circ}$ Figure $^{\circ} 3 \mathrm{a}^{\circ}{ }^{\circ}$ the ${ }^{\circ} \mathrm{MS}^{\circ}$ signal $^{\circ}$ of ${ }^{\circ}$ the ${ }^{\circ}$ phosphorylated peptides enriched by the PAA membrane is remarkably improved. Careful examination of the spectra using the automatic $\mathrm{S} / \mathrm{N}$ calculation software of the spectrometer shows that the $\mathrm{S} / \mathrm{N}$ ratio for the phosphopeptides enriched by the PAA membrane is about sixfold better than that directly deposited onto the PAA target. Almost no other unphosphorylated peptides appear ${ }^{\circ}$ in $^{\circ}$ Figure $^{\circ} 3 b^{\circ}{ }^{\circ}$ clearly $^{\circ}$ indicating ${ }^{\circ}$ that ${ }^{\circ}$ the ${ }^{\circ}$ PAA membrane can specifically adsorb and selectively enrich the phosphorylated peptides from the tryptic digest mixture. The enrichment experiment was also performed using $\alpha$-casein as a model phosphoprotein. The enriching effect toward phosphopeptides was also observed (results not shown). All these results confirm that the PAA membrane has specific absorption ability toward phosphopeptides, although nonphosphopeptides are present in solution.

In our previous report, we studied the electroosmotic flow of PAA membranes and found that the PAA membrane has stronger incorporation ability toward the ${ }^{\circ}$ phosphate $^{\circ}$ anions $^{\circ}[42] .{ }^{\circ} \mathrm{As}^{\circ}$ shown $^{\circ}$ by $^{\circ}$ the ${ }^{\circ}$ solution $\mathrm{pH}$-dependent electroosmotic velocity, the isoelectric 


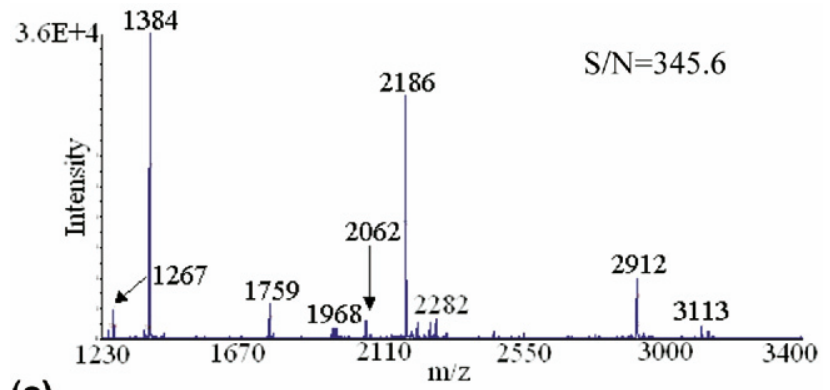

(a)

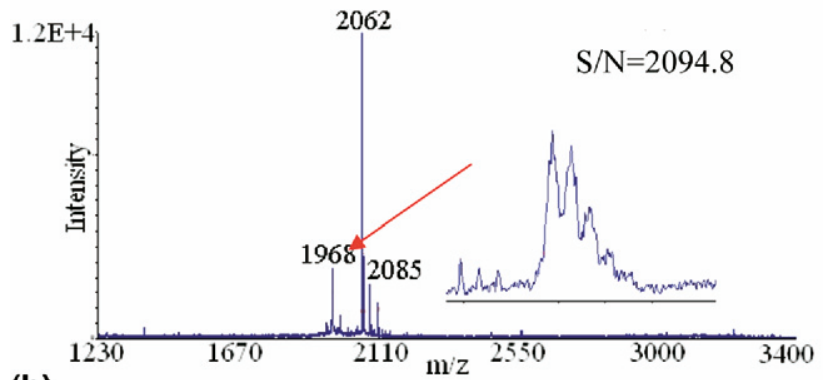

(b)

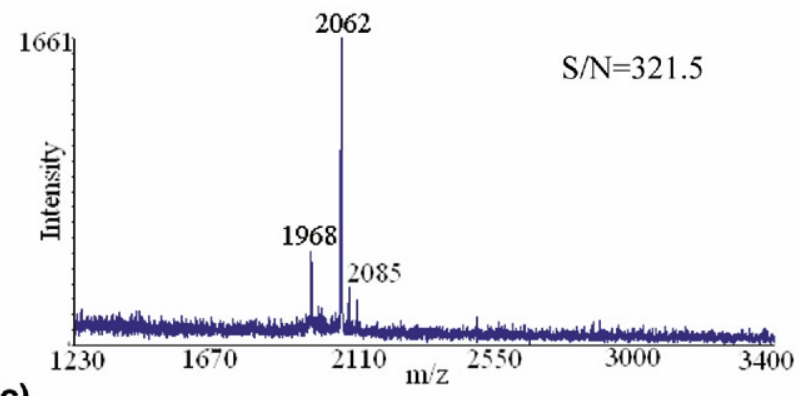

(c)

Figure 3. MALDI mass spectra of the tryptic digest product of $\beta$-casein deposited on the PAA target $(\mathbf{a})$. Spectra (b, c) corresponded to the tryptic digest product of $\beta$-casein enriched by the PAA membrane for $6 \mathrm{~h}$ at the following concentrations: (b) $2 \times$ $10^{-6} \mathrm{M}$; (c) $4 \times 10^{-9} \mathrm{M}$. Saturated CHCA in a mixture of 50:50 water/acetonitrile (vol:vol) with $0.1 \%$ trifluoroacetic acid was used as matrix for MALDI-TOF MS analysis. PAA membranes were obtained by constant-voltage anodization at $120 \mathrm{~V}$ in $0.2 \mathrm{M}$ phosphate acid. The insert is attributed to the metastable loss of $\mathrm{H}_{3} \mathrm{PO}_{4}$ from the parent ion ( $\left.\mathrm{m} / \mathrm{z} 2062\right)$.

point of the PAA membrane made in phosphate acid solution in Tris- $\mathrm{HCl}$ buffer is located at around 5.5 (Figure ${ }^{\circ} 4,{ }^{\circ}$ curve $^{\circ}$ b).$^{\circ}{ }^{\circ} t^{\circ}$ shifts $^{\circ}$ to ${ }^{\circ}$ about ${ }^{\circ} 3.7^{\circ}$ in $^{\circ} \mathrm{a}^{\circ}$ phosphate buffer ${ }^{\circ}$ in $^{\circ} a^{\circ}$ few $^{\circ}$ seconds $^{\circ}\left(\right.$ Figure $^{\circ} 4,{ }^{\circ}$ curve $\left.^{\circ} \mathrm{d}\right) .{ }^{\circ}$ The ${ }^{\circ}$ variation of isoelectric point is attributed to the specific adsorption of phosphate anions by electrostatic interactions (or ion exchange). The specific interactions between the phosphate ions and the PAA membrane might be used to explain the selective enrichment of phosphopeptide ${ }^{\circ}$ in $^{\circ}$ Figure $^{\circ} 3 \mathrm{~b}^{\circ}$ and ${ }^{\circ} \mathrm{c}^{\circ}{ }^{\circ}$ The $^{\circ}$ phosphate moiety of the phosphopeptide specifically interacts with the PAA membrane, resulting in selective enrichment of phosphopeptide. NMR study also shows that the phosphate moiety of the phosphopeptide specifically interacts with aluminum ion (results not shown). Compared to the phosphate anion-exchanging results, the enrichment process for phosphopeptiede is relatively slow (results not shown), which could be explained by the steric hindrance of the nanochannel, the complexed charge distribution of the phosphopeptiede, or the slow exchange between nonphosphopeptides and the phosphopeptides at the PAA interface. As the PAA contacts with the mixture solution, at the beginning, both the nonphosphopeptides and phosphopeptides can adsorb onto the PAA surface by nonspecific and specific interactions, respectively. As a result of the latter, interaction is stronger than that of the former process; phosphopeptides will replace the competitively adsorbed nonphosphopeptides from the PAA membrane. This replacement process could be very slow, but it determines the phosphopeptide enrichment efficiency. This phenomenon was confirmed by the increase of $\mathrm{S} / \mathrm{N}$ ratio for the phosphopeptides with the enriching time.

The phosphopeptide peak at $\mathrm{m} / \mathrm{z} 2062$ enriched from the tryptic digest product of $\beta$-casein at $4 \times 10^{-9} \mathrm{M}$ remains ${ }^{\circ}$ significant ${ }^{\circ}{ }^{\circ}{ }^{\circ}$ the $^{\circ} \mathrm{MALDI}^{\circ} \mathrm{mass}^{\circ}$ spectrum ${ }^{\circ}$ (Fig-

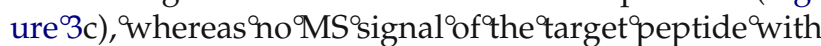
the direct deposition method appears. In this case, the $\mathrm{S} / \mathrm{N}$ ratio for the phosphopeptide is still satisfactory after enrichment by the PAA membrane. This detection concentration is about one to two orders of magnitude lower than the traditional IMAC combined with MALDI-TOF MS approach (results not shown). The tryptic digest product of $\beta$-casein enriched by the ZipTipMC (Millipore, Billerica, MA, USA) and enriched by the PAA membrane for $6 \mathrm{~h}$ were detected at the same concentration of $2.5 \times 10^{-8} \mathrm{M}$. The calculated S/N ratios for the phosphopeptide are 180.5 for enrichment by the ZipTipMC and 959.8 for enrichment by the PAA membrane. The tryptic digest product of $\beta$-casein at the concentration as low as $4 \times 10^{-9} \mathrm{M}$ can be satisfactorily detected after enrichment by the PAA membrane,

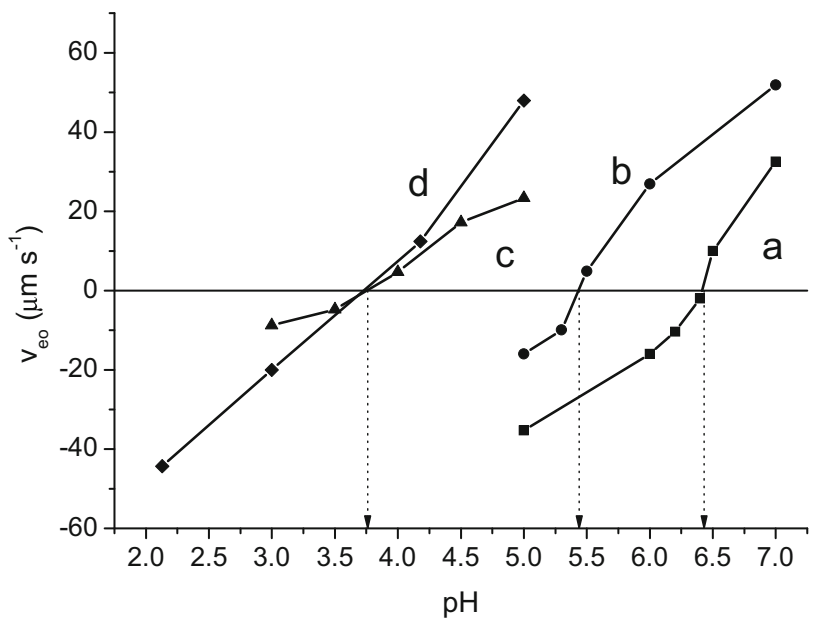

Figure 4. Plots of electroosmotic velocity at applied transmembrane current of $0.5 \mathrm{~mA}$ in curves a, b Tris- $\mathrm{HCl}$ and curves c, d phosphate buffer solution $(0.02 \mathrm{M})$ as a function of solution $\mathrm{pH}$. PAAMs were obtained by constant-voltage anodization curves a, c at $60 \mathrm{~V}$ in $0.3 \mathrm{M}$ oxalic acid and curves b, d at $120 \mathrm{~V}$ in $0.2 \mathrm{M}$ phosphoric acid. 
Table 1. Phosphopeptides identified in $\beta$-casein ${ }^{\mathrm{a}}$

\begin{tabular}{lcl}
\hline [MH] $^{+}$ & Peptide residues & \multicolumn{1}{c}{ Phosphopeptide sequence } \\
\hline \hline 2061.83 & $33-48$ & FQ[pS]EEQQOTEDELQDK \\
2556.09 & $33-52$ & FQ[pS]EEQQOTEDELQDKIHPF \\
3122.27 & $1-25$ & RELEELNVPGEIVE[pS]L[pS][pS][pS]EESITR \\
\hline
\end{tabular}

${ }^{\mathrm{a}}$ From Stensballe and Jensen [44].

whereas no signal of phosphopeptide can be detected after enrichment by the ZipTipMC. The high enriching capacity must be ascribed to the extremely large surface area and good biocompatibility of the PAA membrane $\left[40,{ }^{\circ} 41\right] . .^{\circ}$ The $^{\circ}$ results ${ }^{\circ}$ demonstrate ${ }^{\circ}$ that ${ }^{\circ}$ the $^{\circ} \mathrm{PAA}^{\circ} \mathrm{mem}^{-}$ brane could be an alternative material for the selective enrichment of phosphopeptides with high efficiency.

Monophosphopeptide ( $m / z 2061.89 \mathrm{Da}, \mathrm{m} / \mathrm{z} 2555.76)$ and tetraphosphopeptide $(\mathrm{m} / \mathrm{z} 3122.11 \mathrm{Da})$ represent phosphopeptide $^{\circ}$ residues $^{\circ}$ derived $^{\circ}$ from $^{\circ} \beta$-casein ${ }^{\circ}[44]$ (see ${ }^{\circ}$ Table $\left.{ }^{\circ} 1\right) .{ }^{\circ}$ However, ${ }^{\circ}$ the ${ }^{\circ} \mathrm{MS}^{\circ}$ signal ${ }^{\circ}$ from $^{\circ}$ the ${ }^{\circ}$ tetraphosphopeptide ${ }^{\circ} s^{\circ}$ not $^{\circ}$ observed $^{\circ}{ }^{\circ}{ }^{\circ}$ Figure 3 . This ${ }^{\circ}$ could be $^{\circ}{ }^{\circ}{ }^{\circ}$ result ${ }^{\circ}$ of ${ }^{\circ}$ the ${ }^{\circ}$ strong ${ }^{\circ}$ signal $^{\circ}$ suppression $[14,45,46]$, and/or the high binding force between the tetraphosphopeptide and the PAA membrane. These effects would make the ionization of tetraphosphopeptide under the positive MS mode difficult. However, when we used o-phosphoric acid as the acid dopant in DHB as the matrix, the MS signal of tetraphosphopeptide $(\mathrm{m} / \mathrm{z}$ $3122)$ and another phosphopeptide $(\mathrm{m} / \mathrm{z} 2556)$ were observed ${ }^{\circ}$ after ${ }^{\circ}$ the ${ }^{\circ}$ enrichment ${ }^{\circ}$ process ${ }^{\circ}$ with $^{\circ}{ }^{\circ} A^{\circ}{ }^{\circ}$ (Figure $\left.{ }^{\circ} 5\right) .{ }^{\circ}{ }^{\circ} n^{\circ}$ addition ${ }^{\circ} o^{\circ}$ the ${ }^{\circ}$ enhanced ${ }^{\circ}$ ionization ${ }^{\circ}$ of ${ }^{\circ}$ phosphopeptide, phosphoric acid might decrease the interactions between the PAA membrane and the tetraphosphopeptide. Therefore, the tetraphosphorylated peptide species are efficiently eluted from the PAA membrane and can be satisfactorily detected under $^{\circ}$ acidic, ${ }^{\circ}$ neutral, ${ }^{\circ}$ and $^{\circ}$ alkaline $^{\circ}$ conditions $^{\circ}$ (Figure $5 \mathrm{~b}-\mathrm{d}) .^{\circ} \mathrm{The}^{\circ} \mathrm{MS}^{\circ}$ signals $^{\circ}$ of ${ }^{\circ}$ tetraphosphopeptide ${ }^{\circ}(\mathrm{m} / \mathrm{z}$ $3122, \mathrm{~m} / \mathrm{z} 3146$, and $\mathrm{m} / \mathrm{z} 3170$ ) correspond to the $[\mathrm{MH}]^{+}$, $[\mathrm{MH}+\mathrm{Al}-3 \mathrm{H}]^{+}$, and $[\mathrm{MH}+2 \mathrm{Al}-6 \mathrm{H}]^{+}$, respectively. Commercial PAA membrane (diameter: $13 \mathrm{~mm}$, pore size: $0.1 \mu \mathrm{m}$; Whatman International Ltd, Kent, UK), prepared in phosphoric acid, has also been applied to the enrichment experiments. The same results were obtained as those of the self-prepared PAA membranes (results not shown). All these results confirm that PAA membranes made in phosphoric acid have specific absorption ability toward phosphopeptides.

Alumina is an amphoteric material whose surface electrical ${ }^{\circ}$ properties ${ }^{\circ}$ depend ${ }^{\circ}$ on solution ${ }^{\circ} \mathrm{pH}^{\circ}$ [47] ${ }^{\circ}$ and the isoelectric point of the amorphous alumina is $\mathrm{pH} \simeq 8$ [48]. ${ }^{\circ}$ If $^{\circ}$ the ${ }^{\circ}$ interactions ${ }^{\circ}$ between ${ }^{\circ}$ the ${ }^{\circ}$ phosphopeptides and the PAA membrane are mainly by electrostatic interactions, the enrichment capacity would be influenced by solution $\mathrm{pH}$. The isoelectric point of the PAA membrane made in phosphate acid is about 5.5 in Tris- $\mathrm{HCl}^{\circ}$ buffer ${ }^{\circ}[42] .^{\circ}$ Thus, $^{\circ}$ at $^{\circ} \mathrm{pH}^{\circ}<{ }^{\circ} 5.5,{ }^{\circ}$ the ${ }^{\circ}$ PAA membrane is protonated and has a positively charged surface. In contrast, the PAA membrane has an overall negatively charged surface in $\mathrm{pH}>5.5$. In principle, because the solution $\mathrm{pH}$ is higher above 5.5 , the absorption capacity must decrease because of the electrostatic repulsive interaction between the negatively charged surface of the PAA membrane and the negative charge of ${ }^{\circ}$ the ${ }^{\circ}$ phosphopeptides. ${ }^{\circ}$ However, ${ }^{\circ} a^{\circ}{ }^{\circ}$ shown ${ }^{\circ}$ in ${ }^{\circ}$ Figure $5,{ }^{\circ}$ the ${ }^{\circ}$ enrichment ${ }^{\circ}$ process $^{\circ}$ has $^{\circ}$ almost $^{\circ}$ no $^{\circ}$ pertinence ${ }^{\circ}$ to $\mathrm{pH}$; the interactions between the phosphopeptides and the PAA membrane must be the result of a specific adsorption of phosphate anions mainly by ion exchange, and electrostatic interactions can be neglected.

The abundances of the protonated phosphorylated peptide in the MALDI mass spectrum of the tryptic digest $^{\circ}{ }^{\circ} f^{\circ} \beta$-casein ${ }^{\circ}$ shown $^{\circ}$ in $^{\circ}$ Figure $^{\circ} 3 b^{\circ}$ are ${ }^{\circ}$ high ${ }^{\circ}$ enough for $^{\circ}$ the ${ }^{\circ} \mathrm{PSD}^{\circ} \mathrm{MS}^{\circ}$ analysis. ${ }^{\circ}$ Figure $^{\circ} 6^{\circ}$ displays ${ }^{\circ}$ the ${ }^{\circ} \mathrm{PSD}$ mass spectrum of the sample obtained using PAA membrane to enrich target peptides from the tryptic digest product of $\beta$-casein. Beside the peak at $m / z 2062$ $\left([\mathrm{MH}]^{+}\right)$, a fragment ion at $\mathrm{m} / \mathrm{z} 1964$ corresponding to the elimination of a $\mathrm{H}_{3} \mathrm{PO}_{4}(\mathrm{~m} / z$ 98) appears. This result confirms the peak at $m / z 2062$ from a phosphopeptide.

\section{Selective Enrichment of Phosphopeptide Using PAA Membranes Prepared in Other Acids}

We also studied the selective enrichment of phosphopeptide on PAA membranes prepared in oxalic acid. ${ }^{\circ} \mathrm{As}^{\circ}$ shown $^{\circ}$ in $^{\circ}$ Figure $^{\circ} 7 \mathrm{a},{ }^{\circ}$ the ${ }^{\circ}$ enrichment $^{\circ}$ process also occurs. However, the enriching effect on the phosphopeptides is insignificant compared to that of the PAA $^{\circ}$ membranes $^{\circ}$ prepared $^{\circ}$ in $^{\circ}$ phosphoric $^{\circ}$ acid $^{\circ}$ (Figure 3b). ${ }^{\circ}$ This $^{\circ}$ enrichment $^{\circ}$ effect $^{\circ}$ must $^{\circ}$ be $^{\circ} a^{\circ}$ result $^{\circ}$ of $^{\circ}$ the phosphate moiety of the phosphopeptide, which could replace the oxalic anion adsorbed on the PAA membrane, resulting in the enrichment of phosphopeptide (Figure $\left.{ }^{\circ} 7 \mathrm{a}\right){ }^{\circ}{ }^{\circ}$ Such $^{\circ}$ an $^{\circ}$ ion-exchange ${ }^{\circ}$ effect $^{\circ}$ has $^{\circ}$ been $^{\circ}$ observed ${ }^{\circ}{ }^{\circ}{ }^{\circ}{ }^{\circ}{ }^{\circ}$ previous $^{\circ}$ work $^{\circ}[42] .{ }^{\circ}$ The ${ }^{\circ}$ isoelectric ${ }^{\circ}$ point of PAA membrane made in oxalic acid is about 6.5 (Figure $^{\circ} 4,{ }^{\circ}$ curve $^{\circ}$ a) ${ }^{\circ}$ The $^{\circ}$ isoelectric ${ }^{\circ}$ point $^{\circ}$ of $^{\circ}$ this ${ }^{\circ}$ PAA membrane shifts to about 3.7 in a phosphate buffer

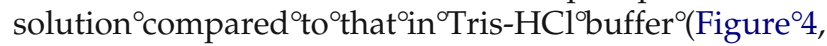
curve c). This change of the isoelectric point arises from the adsorption of phosphate anions by electrostatic interactions (or ion exchange), indicating that the PAA membrane has a stronger incorporation ability toward phosphate anions than toward oxalic anions. However, if the PAA membrane was immersed in a phosphate buffer $^{\circ}\left(\mathrm{pH}^{\circ}={ }^{\circ} 7.0\right)^{\circ}$ for $^{\circ} 1^{\circ} \mathrm{h}^{\circ}\left(\right.$ Figure $\left.^{\circ} 7 \mathrm{~b}\right){ }^{\circ}{ }^{\circ}$ it $^{\circ}$ displays $^{\circ} \mathrm{a}$ significant MS signal of phosphopeptide. That is be- 

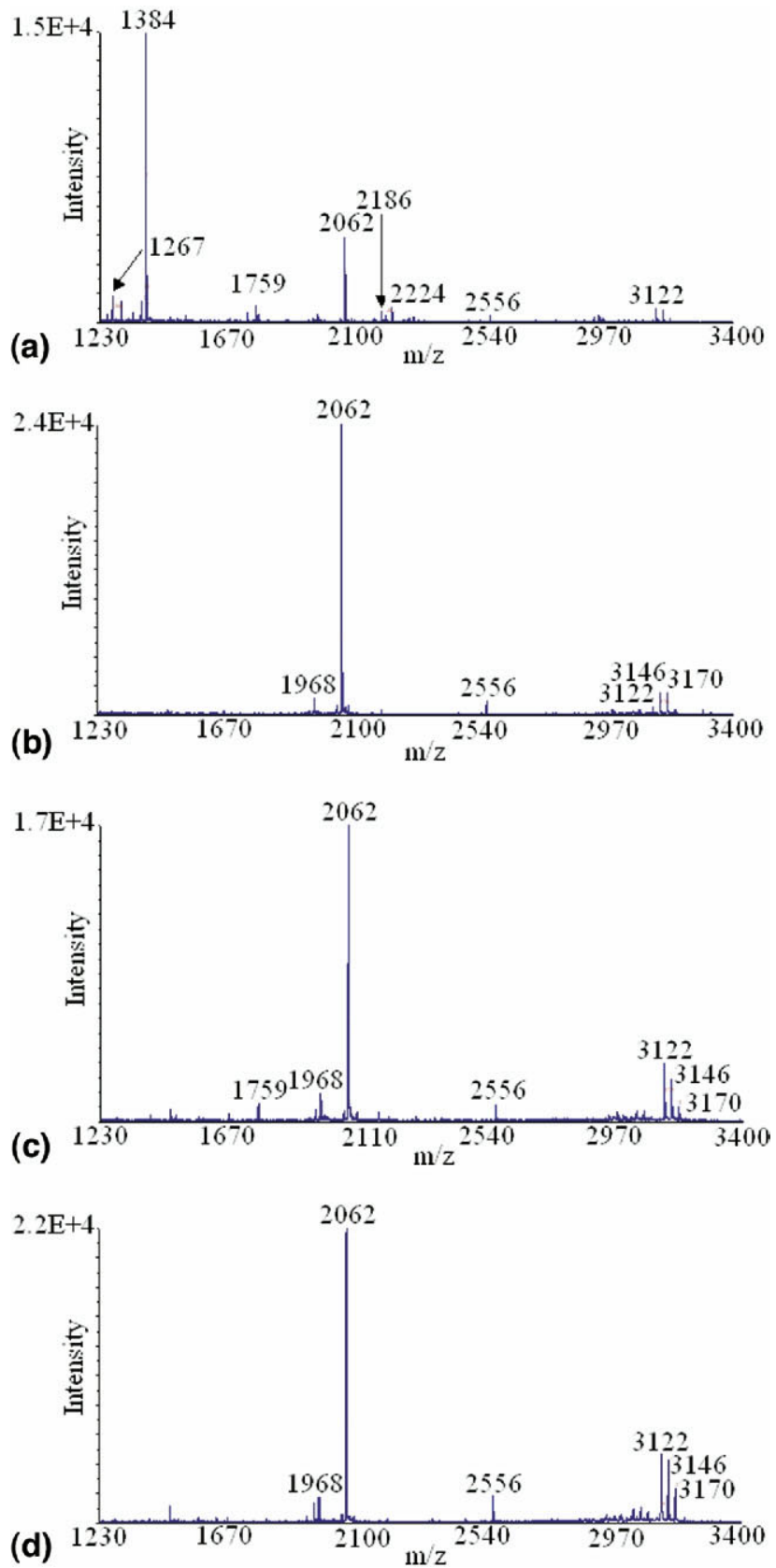

Figure 5. MALDI mass spectra of the tryptic digest product of $\beta$-casein $\left(1 \times 10^{-7} \mathrm{M}\right)$ directly deposited on the PAA target $(\mathbf{a})$. Spectra $(\mathbf{b}-\mathbf{d})$ respectively correspond to the tryptic digest product of $\beta$-casein $\left(1 \times 10^{-7} \mathrm{M}\right)$ enriched by the PAA membrane for $6 \mathrm{~h}$ under the following conditions: (b) in a mixture of 7:3 water/ acetonitrile (vol:vol) with $0.1 \%$ trifluoroacetic acid; (c) in a mixture of 7:3 water/acetonitrile (vol:vol); (d) in a mixture of 7:3 $\mathrm{NH}_{4} \mathrm{HCO}_{3}$ /acetonitrile (vol:vol). 2,5-DHB $(20 \mathrm{mg} / \mathrm{mL}$ ) in $50 \%$ acetonitrile $/ 1 \%$ phosphoric acid was used as matrix for MALDITOF MS analysis. PAA membranes were obtained by constantvoltage anodization at $120 \mathrm{~V}$ in $0.2 \mathrm{M}$ phosphate acid. The MS signals of tetraphosphopeptide $(\mathrm{m} / \mathrm{z} 3122, \mathrm{~m} / \mathrm{z} 3146$, and $\mathrm{m} / \mathrm{z} 3170)$ correspond to the $[\mathrm{MH}]^{+},[\mathrm{MH}+\mathrm{Al}-3 \mathrm{H}]^{+}$, and $[\mathrm{MH}+2 \mathrm{Al}-6 \mathrm{H}]^{+}$, respectively.

cause the ion exchange between the oxalic anions on the PAA membrane and the phosphate ions in the phosphate ${ }^{\circ}$ buffer ${ }^{\circ}$ occurred $^{\circ}\left(\right.$ Figure $^{\circ} 4,{ }^{\circ}$ Curves $^{\circ} \mathrm{a}^{\circ}$ and $\left.^{\circ} \mathrm{C}\right){ }^{\circ}{ }^{\circ}$ So $^{\circ}$ the

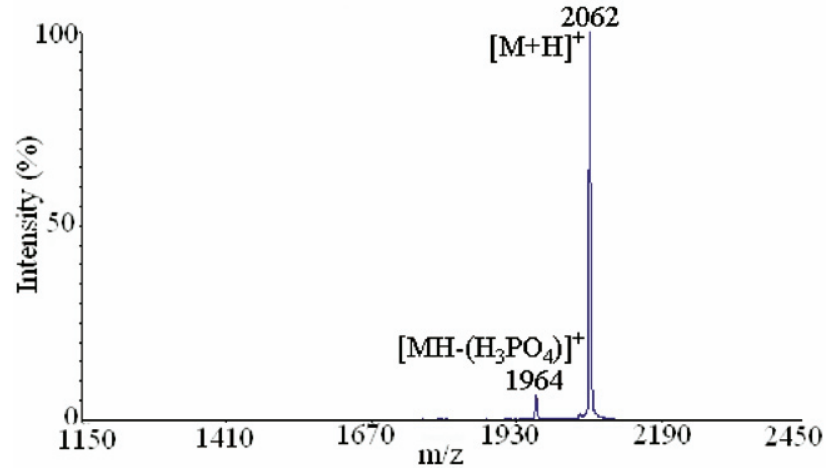

Figure 6. PSD mass spectrum of the sample obtained using PAA membrane to enrich target peptides from the tryptic digest product of $\beta$-casein $\left(10^{-6} \mathrm{M}\right)$. PAA membranes were obtained by constant-voltage anodization at $120 \mathrm{~V}$ in $0.2 \mathrm{M}$ phosphate acid.

mechanism of the enhanced enrichment process is the same as that of PAA membrane prepared in phosphate acid. Because the interaction between phosphopeptides and the PAA membrane prepared in oxalic acid was weaker than that of phosphopeptides and the PAA membrane ${ }^{\circ}$ prepared ${ }^{\circ}{ }^{\circ}{ }^{\circ}$ phosphate ${ }^{\circ}$ acid $^{\circ}\left(\right.$ see $^{\circ}$ Figures $^{\circ} 3 \mathrm{~b}$ and $^{\circ} 7$ a). ${ }^{\circ} \mathrm{So}^{\circ}$ the ${ }^{\circ}$ high $^{\circ}$ binding $^{\circ}$ force ${ }^{\circ}$ between ${ }^{\circ}$ the ${ }^{\circ}$ phosphopeptide $(\mathrm{m} / \mathrm{z} 2556)$ and the PAA membrane would make the ionization of phosphopeptide under the positive ${ }^{\circ} \mathrm{MS}^{\circ}$ mode ${ }^{\circ}$ difficult $^{\circ}$ (Figure $\left.7 \mathrm{~b}\right) .{ }^{\circ}$ However, ${ }^{\circ}$ when ${ }^{\circ}$ we used o-phosphoric acid as the acid dopant in DHB as the matrix, the MS signal of phosphopeptide $(\mathrm{m} / \mathrm{z} 2556)$

(a)
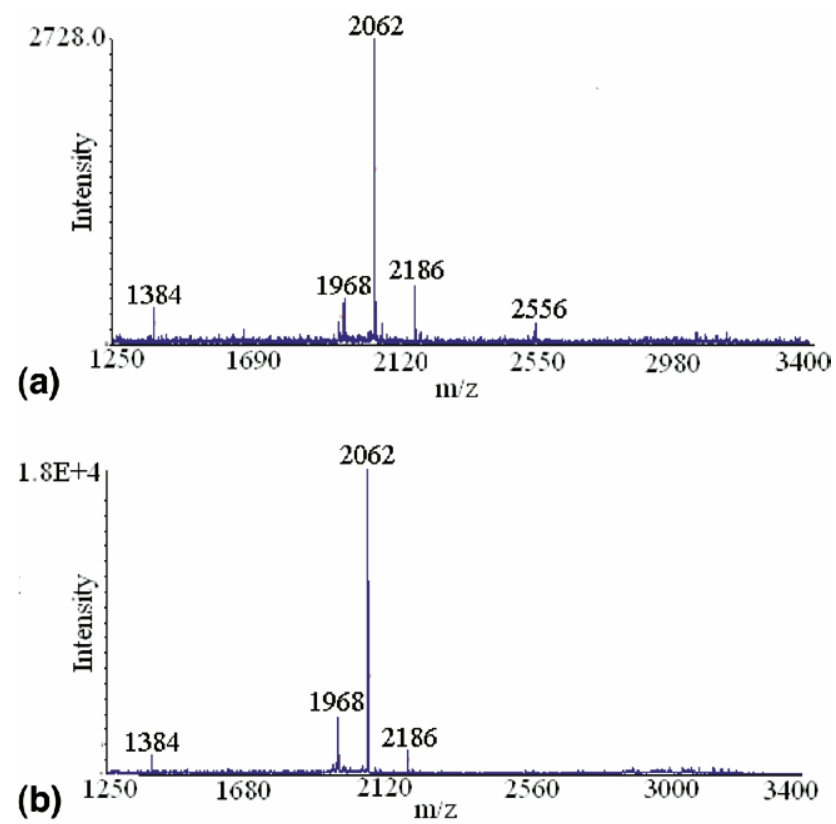

Figure 7. The enriching effect of PAA membrane made in oxalic acid toward phosphopeptides. PAA membrane immersed in phosphate buffer $(\mathrm{pH}=7.0)$ for $0 \mathrm{~h}$ (a) and immersed in phosphate buffer $(\mathrm{pH}=7.0)$ for $1 \mathrm{~h}(\mathbf{b})$. Saturated CHCA in a mixture of 50:50 water/acetonitrile (vol:vol) with $0.1 \%$ trifluoroacetic acid was used as matrix for MALDI-TOF MS analysis. PAA membranes were obtained by constant-voltage anodization at $60 \mathrm{~V}$ in $0.3 \mathrm{M}$ oxalic acid. 
Table 2. Peptide sequence, molecular weight, and isoelectric point of the two acidic peptides

\begin{tabular}{llcr}
\hline Acidic peptides $^{\text {a }}$ & Peptide sequence & Molecular weight & Isoelectric point \\
\hline \hline Peptide 1 & EDVGSNKGAIIGLM & 1403.60 & 4.37 \\
Peptide 2 & VYPNGAEDESAEAFPLEF & 1985.06 & 3.45 \\
\hline
\end{tabular}

Both of these peptides contain acidic amino acids possessing carboxylic acid side chains, such as glutamic acid and aspartic acid. The isoelectric point (pl) of peptide 2 is close to that of monophosphopeptide ( $\mathrm{m} / \mathrm{z} 2061.89 \mathrm{Da}$; $\mathrm{pl}=3.29)$ [49]. The pl value of the peptides was calculated by using the ProtParam tool from http://www.expasy.org.

aPeptide 1 and peptide 2 are amyloid $\beta$-protein fragment 22-35 and ACTH 22-39, respectively.

was observed after the enrichment process with PAA membrane $^{\circ}$ prepared $^{\circ}$ in $^{\circ}$ phosphate $^{\circ}$ acid $^{\circ}\left(\right.$ Figure $\left.\left.^{\circ}\right)\right)^{\circ}$ As described earlier, phosphoric acid might decrease the interactions between the PAA membrane and the phosphopeptide besides enhancing ionization of phosphopeptide. Therefore, the phosphorylated peptide species are efficiently eluted from the PAA membrane and can be satisfactorily detected. All the results imply that the phosphate anions adsorbed on the PAA membrane play a determining role in achieving highly selective enriching capacity toward phosphopeptides.

\section{Study of Selective Capacity of PAA Membranes toward Phosphopeptides}

For better understanding of the selective capacity of PAA membranes toward phosphopeptides, a mixture of $^{\circ}$ acidic $^{\circ}$ peptides $^{\circ}\left(\text { see }^{\circ} \text { Table }^{\circ} 2\right)^{\circ}$ and $^{\circ}$ tryptic $^{\circ}$ digest $^{\circ}$ of $\beta$-casein was analyzed. Trace phosphopeptide derived from $\beta$-casein can be effectively enriched by the PAA membrane, even when the amount of acidic peptides is $20^{\circ}$ higher $^{\circ}$ than $^{\circ}$ that $^{\circ}{ }^{\circ} f^{\circ} \beta$-casein ${ }^{\circ} \operatorname{digest}^{\circ}\left(\right.$ Figure $^{\circ} 8$ a). ${ }^{\circ}$ The MS signal of the phosphopeptide becomes prominent after enrichment, whereas only a scant MS signal of acidic peptide $(\mathrm{m} / \mathrm{z} 1986)$ containing five acidic amino acids residues appears in the mass spectrum and the MS signal of another acidic peptide $(\mathrm{m} / \mathrm{z}$ 1405) containing two acidic amino acids residues does not appear. If the concentrations of the acidic peptides and tryptic digest products of $\beta$-casein are almost equal, the phosphopeptide dominates the mass spectra after performing the enriching process and no MS signal of acidic peptide ${ }^{\circ}$ appears ${ }^{\circ}\left(\right.$ Figure $^{\circ} 8 \mathrm{~b}^{\circ}$ and $\left.{ }^{\circ} \mathrm{C}\right) . .^{\circ}$ These $^{\circ}$ results ${ }^{\circ}$ indicate that, in addition to phosphopeptides, the PAA membrane has a somewhat enriching capacity toward some other acidic peptide residues. The mixture of the tryptic digest products of cytochrome $C$ and $\beta$-casein was also analyzed to evaluate the effectiveness of the selective sampling technique in enriching the phosphopeptides (results not shown). As expected, the results were similar to those of the mixture of acidic peptides and the tryptic digest products of $\beta$-casein (Figure 8 ). Trace ${ }^{\circ}$ hosphopeptide ${ }^{\circ}$ derived ${ }^{\circ}$ from ${ }^{\circ} \beta$-casein can be effectively enriched by the PAA membrane, even when the amount of cytochrome $C$ digest is 20 higher than that of $\beta$-casein. The MS signal of phosphopeptide becomes prominent after enrichment, whereas only a scant MS signal of nonphosphorylated peptide derived from cytochrome C $(\mathrm{m} / \mathrm{z} 1496, \mathrm{pI}=4.09)$ appears. The peaks located at $\mathrm{m} / \mathrm{z} 1496$ correspond to the peptide residues of cytochrome $\mathrm{C}$, which contains four glutamic acid residues. If the concentrations of the tryptic digest products of cytochrome $C$ and $\beta$-casein are almost equal, the phosphopeptide dominates the mass spectra after performing the enriching process, whereas no other nonphosphorylated peptides appear in the mass
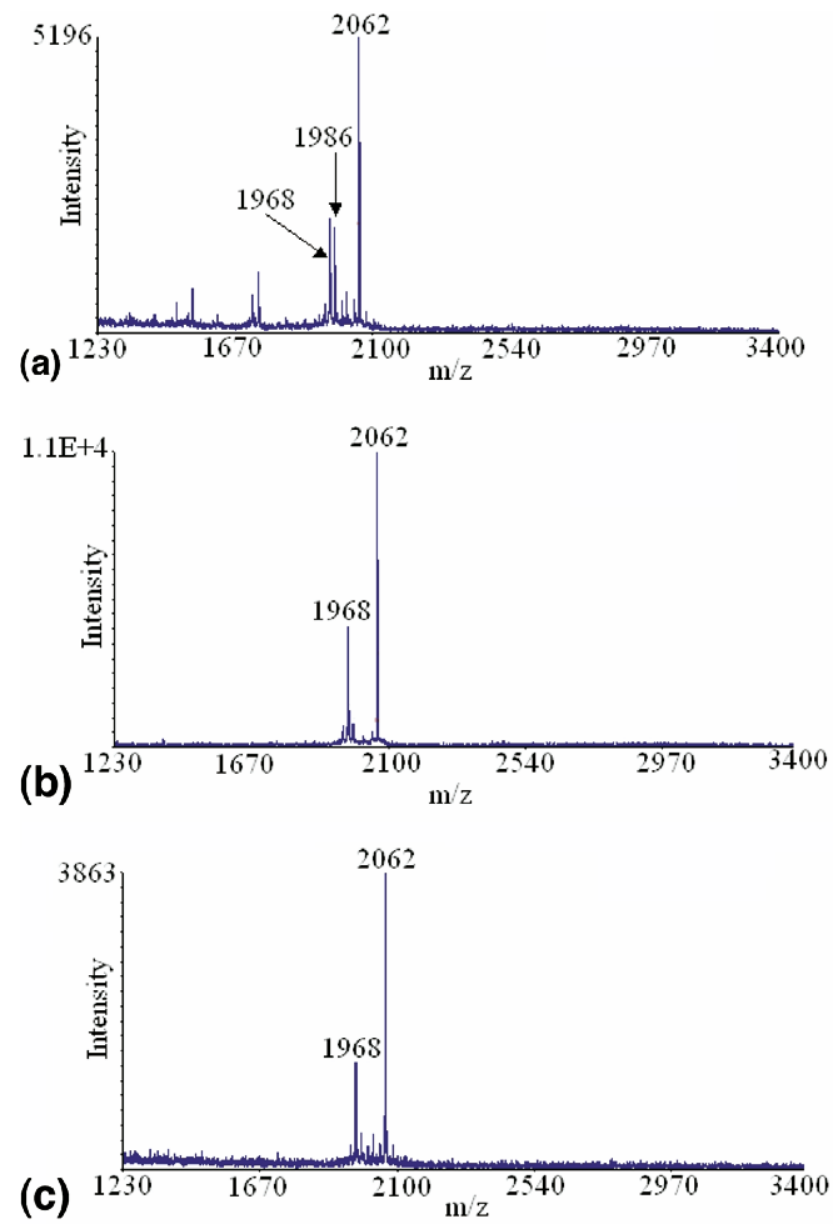

Figure 8. MALDI mass spectra of the samples enriched by the PAA membranes for $6 \mathrm{~h}$ from a mixture of two acidic peptides (1 $\left.\times 10^{-6} \mathrm{M}\right)$ and the tryptic digest product of $\beta$-casein $\left(5 \times 10^{-8} \mathrm{M}\right)$ (a). Spectra $(\mathbf{b}, \mathbf{c})$ respectively correspond to a mixture of two acidic peptides and the tryptic digest product of $\beta$-casein enriched by the PAA membrane for $6 \mathrm{~h}$ under the same concentrations: (b) $1 \times 10^{-6} \mathrm{M}$; (c) $2.5 \times 10^{-8} \mathrm{M}$. Saturated CHCA in a mixture of 50:50 water/acetonitrile (vol:vol) with $0.1 \%$ trifluoroacetic acid was used as matrix for MALDI-TOF MS analysis. PAA membranes were obtained by constant-voltage anodization at $120 \mathrm{~V}$ in $0.2 \mathrm{M}$ phosphate acid. 
spectrum. Although the MS signal of acidic peptides is detectable, it accounts for only a minor percentage compared to that of phosphopeptides. Obviously, acidic peptides have an insignificant influence on the enriching process. On the whole, the PAA membrane has a high specificity toward phosphopeptides.

\section{Conclusions}

For the first time we have made use of the good biocompatibility, high surface-to-volume ratio, and distinct surface electrical properties of porous anodic alumina membranes to selectively enrich phosphopeptides from a mixture of synthetic peptides and tryptic digest product of $\beta$-casein by a direct MALDI-TOF MS analysis. Because the PAA membrane has specific absorption ability toward the phosphopeptides, the tryptic digest product of $\beta$-casein at a concentration as low as $4 \times$ $10^{-9} \mathrm{M}$ can be satisfactorily detected after enriched by the PAA membranes. Results also show that the adsorption of phosphate anions on the PAA membrane plays a determining role in achieving highly selective enriching capacity toward phosphopeptides. Because of the easy preparation and low cost of the PAA membranes, the present method is promising for sensitive and effective analysis of phosphorylation in proteomics research.

\section{Acknowledgments}

This work was supported by National Natural Science Foundation of China Grants 20125515, 20375016, 20535010, 20175034, and 20475059; National Science Fund for Creative Research Groups Grant 20521503; and Chinese Academy of Science Grant KGCX2SW-213-04. The authors thank Dr. Z.-Y. Liu (Research Center for Proteome Analysis, Shanghai Institutes for Biological Sciences, Chinese Academy of Sciences, Shanghai, China) for his helpful discussion.

\section{References}

1. Koch, C. A.; Anderson, D.; Moran, M. F.; Ellis, C.; Pawson, T. SH2 and SH3 Domains: Elements That Control Interaction of Cytoplasmic Signalling Proteins. Science 1991, 252, 668-674.

2. Pawson, T.; Scott, J. D. Signaling through Scaffold, Anchoring, and Adaptor Proteins. Science 1997, 278, 2075-2080.

3. Hunter, T. Signaling-2000 and Beyond. Cell 2000, 100, 113-127.

4. Zolnierowicz, S.; Bollen, M. Protein Phosphorylation and Protein Phosphatases. EMBO J. 2000, 19, 483-488.

5. Wettenhall, R. E.; Aebersold, R. H.; Hood, L. E. Solid-Phase Sequencing of ${ }^{32} \mathrm{P}$ Labelled Phosphopeptides. Methods Enzymol. 1991, 201, 186-199.

6. Zhang, H.; Zha, X. M.; Tan, Y.; Hornbeck, P. V.; Mastrangelo, A. J.; Alessi, D. R.; Polakiewicz, R. D.; Comb, M. J. Phosphoprotein Analysis Using Antibodies Broadly Reactive against Phosphorylated Motifs. J. Biol. Chem. 2002, 277, 39379-39387.

7. Gatti, A.; Li, H. H.; Traugh, J. A.; Liu, X. Phosphorylation of Human p53 on Thr-55. Biochemistry 2000, 39, 9837-9842.

8. Yan, J. X.; Packer, N. H.; Gooley, A. A.; Williams, K. L. Protein Phosphorylation: Technologies for the Identification of Phosphoamino Acids. J. Chromatogr. A 1998, 808, 23-41.

9. Chalmers, M. J.; Kolch, W.; Emmett, M. R.; Marshall, A. G.; Mischak, H. Identification and Analysis of Phosphopeptides. J. Chromatogr. B 2004, 803, 111-120.

10. McLachlin, D. T.; Chait, B. T. Analysis of Phosphorylated Proteins and Peptides by Mass Spectrometry. Curr. Opin. Chem. Biol. 2001, 5, 591-602.

11. Kebarle, P. A Brief Overview of the Present Status of the Mechanisms Involved in Electrospray Mass Spectrometry. J. Mass Spectrom. 2000, 35, $804-817$.

12. Liao, P. C.; Leykam, J.; Andrews, P. C.; Gage, D. A.; Allison, J. An Approach to Locate Phosphorylation Sites in a Phosphoprotein: Mass
Mapping by Combining Specific Enzymatic Degradation with Matrix-Assisted Laser Desorption/Ionization Mass Spectrometry. Anal. Biochem. 1994, 219, 9-20.

13. Mann, M.; Ong, S. E.; Gronborg, M.; Steen, H.; Jensen, O. N.; Pandey, A. Analysis of Protein Phosphorylation Using Mass Spectrometry: Deciphering the Phosphoproteome. Trends Biotechnol. 2002, 20, 261-268.

14. Zhou, W.; Merrick, B. A.; Khaledi, M. G.; Tomer, K. B. Detection and Sequencing of Phosphopeptides Affinity Bound to Immobilized Metal Ion Beads by Matrix-Assisted Laser Desorption/Ionization Mass Spectrometry. J. Am. Soc. Mass Spectrom. 2000, 11, 273-282.

15. Trojer, L.; Stecher, G.; Feuerstein, I.; Lubbad, S.; Bonn, G. K. Characterisation and Evaluation of Metal-Loaded Iminodiacetic Acid-Silica of Different Porosity for the Selective Enrichment of Phosphopeptides. J. Chromatogr. A 2005, 1079, 197-207.

16. Zhang, Y. H.; Yu, X. J.; Wang, X. Y.; Shan, W.; Yang, P. Y.; Tang, Y. Zeolite Nanoparticles with Immobilized Metal Ions: Isolation and MALDI-TOF-MS/MS Identification of Phosphopeptides. Chem. Commun. 2004, 24, 2882-2883.

17. Pandey, A.; Podtelejnikov, A. V.; Blagoev, B.; Bustelo, X. R.; Mann, M.; Lodish, H. F. Analysis of Receptor Signaling Pathways by Mass Spectrometry: Identification of Vav-2 as a Substrate of the Epidermal and Platelet-Derived Growth Factor Receptors. Proc. Natl. Acad. Sci. U.S.A. 2000, 97, 179-184.

18. Gronborg, M.; Kristiansen, T. Z.; Stensballe, A.; Andersen, J. S.; Ohara O. Mann, M.; Jensen, O. N.; Pandey, A. A Mass Spectrometry-based Proteomic Approach for Identification of Serine/Threonine-Phosphorylated Proteins by Enrichment with Phospho-specific Antibodies: Identification of a Novel Protein, Frigg, as a Protein Kinase A Substrate. Mol. Cell. Proteomics 2002, 1, 517-527.

19. Andersson, L.; Porath, J. Isolation of Phosphoproteins by Immobilized Metal $\left(\mathrm{Fe}^{3+}\right)$ Affinity Chromatography. Anal. Biochem. 1986, 154, $250-$ 254.

20. Posewitz, M. C.; Tempst, P. Immobilized Gallium (III) Affinity Chromatography of Phosphopeptides. Anal. Chem. 1999, 71, 2883-2892.

21. Kokubu, M.; Ishihama, Y.; Sato, T.; Nagasu, T.; Oda, Y. Specificity of Immobilized Metal Affinity-based IMAC/C18 Tip Enrichment of Phosphopeptides for Protein Phosphorylation Analysis. Anal. Chem. 2005, 77, 5144-5154.

22. Zhou, H. L.; Watts, J. D.; Aebersold, R. A Systemic Approach to the Analysis of Protein Phosphorylation. Nat. Biotechnol. 2001, 19, 375-378.

23. Oda, Y.; Nagasu, T.; Chait, B. T. Enrichment Analysis of Phosphorylated Proteins as a Tool for Probing the Phosphoproteome. Nat. Biotechnol. 2001, 19, 379-382.

24. McLachlin, D. T.; Chait, B. T. Improved $\beta$-Elimination-based Affinity Purification Strategy for Enrichment of Phosphopeptides. Anal. Chem. 2003, 75, 6826-6836.

25. Sano, A.; Nakamura, H. Titania as a Chemo-affinity Support for the Column-switching HPLC Analysis of Phosphopeptides: Application to the Characterization of Phosphorylation Sites in Proteins by Combination with Protease Digestion and Electrospray Ionization Mass Spectrometry. Anal. Sci. 2004, 20, 861-864.

26. Pinkse, M. W. H.; Uitto, P. M.; Hilhorst, M. J.; Ooms, B.; Heck, A. J. R. Selective Isolation at the Femtomole Level of Phosphopeptides from Proteolytic Digests Using 2D-NanoLC-ESI-MS/MS and Titanium Oxide Precolumns. Anal. Chem. 2004, 76, 3935-3943.

27. Chen, C. T.; Chen, Y. C. $\mathrm{Fe}_{3} \mathrm{O}_{4} / \mathrm{TiO}_{2}$ Core/Shell Nanoparticles as Affinity Probes for the Analysis of Phosphopeptides Using $\mathrm{TiO}_{2}$ Surface-Assisted Laser Desorption/Ionization Mass Spectrometry. Anal. Chem. 2005, 77, 5912-5919.

28. Kweon, H. K.; Hakansson, K. Selective Zirconium Dioxide-based Enrichment of Phosphorylated Peptides for Mass Spectrometric Analysis. Anal. Chem. 2006, 78, 1743-1749.

29. Wolschin, F.; Wienkoop, S.; Weckwerth, W. Enrichment of Phosphorylated Proteins and Peptides from Complex Mixtures Using Metal Oxide/Hydroxide Affinity Chromatography (MOAC). Proteomics 2005, 5, 4389-4397.

30. Thompson, G. E.; Fumeaux, R. C.; Wood, G. C.; Richardson, J. A.; Goode, J. S. Nucleation and Growth of Porous Anodic Films on Aluminium. Nature 1978, 272, 433-435

31. Masuda, H.; Fukuda, K. Ordered Metal Nanohole Arrays Made by a Two-Step Replication of Honeycomb Structures of Alumina. Science 1995, 268, 1466-1468.

32. Yuan, J. H.; He, F. Y.; Sun, D. C.; Xia, X. H. A Simple Method for Preparation of Through-hole Porous Anodic Alumina Membrane. Chem. Mater. 2004, 16, 1841-1844.

33. Furneaux, R. C.; Rigby, W. R.; Davidson, A. P. The Formation of Controlled-Porosity Membranes from Anodically Oxidized Aluminium. Nature 1989, 337, 147-149.

34. Masuda, H.; Hasegwa, F.; Ono, S. Self-Ordering of Cell Arrangement of Anodic Porous Alumina Formed in Sulfuric Acid Solution. J. Electrochem. Soc. 1997, 144, L127-L130.

35. Asoh, H.; Nishio, K.; Nakao, M.; Tamamura, T.; Masuda, H. Conditions for Fabrication of Ideally Ordered Anodic Porous Alumina Using Pretextured A1. J. Electrochem. Soc. 2001, 148, B152-B156.

36. Martin, C. R. Nanomaterials: A Membrane-based Synthetic Approach. Science 1994, 266, 1961-1966.

37. Chio, J.; Sauer, G.; Nielsch, K.; Wehspohn, R. B.; Gosele, U. Hexagonally Arranged Monodisperse Silver Nanowires with Adjustable Diameter and High Aspect Ratio. Chem. Mater. 2003, 15, 776-779. 
38. Reiss, B. D.; Freeman, R. G.; Walton, I. D.; Norton, S. M.; Smith, P. C.; Stonas, W. G.; Keating, C. D.; Natan, M. J. Electrochemical Synthesis and Optical Readout of Striped Metal Rods with Submicron Features. J. Electroanal. Chem. 2002, 522, 95-103.

39. Yuan, J. H.; Wang, K.; Xia, X. H. Highly Ordered Platinum Nanotubule Arrays for Amperometric Glucose Sensing. Adv. Funct. Mater. 2005, 15, 803-809.

40. Lau, K. H. A.; Tan, L. S.; Tamada, K.; Sander, M. S.; Knoll, W. Highly Sensitive Detection of Processes Occurring Inside Nanoporous Anodic Alumina Templates: A Waveguide Optical Study. J. Phys. Chem. B 2004, $108,10812-10818$

41. Wang, Y. B.; Xia, X. H.; Guo, Y. L. Porous Anodic Alumina Membrane as a Sample Support for MALDI-TOF MS Analysis of Salt-containing Proteins. J. Am. Soc. Mass Spectrom. 2005, 16, 1488-1492.

42. Chen, W.; Yuan, J. H.; Xia, X. H. Characterization and Manipulation of the Electroosmotic Flow in Porous Anodic Alumina Membranes. Anal. Chem. 2005, 77, 8102-8108.

43. Muller, D. R.; Schindler, P.; Coulot, H.; Voshol, H.; van Oostrum, J. Mass Spectrometric Characterization of Stathmin Isoforms Separated by 2D PAGE. J. Mass Spectrom. 1999, 34, 336-345.
44. Stensballe, A.; Jensen, O. N. Phosphoric Acid Enhances the Performance of Fe (III) Affinity Chromatography and Matrix-Assisted Laser Desorption/Ionization Tandem Mass Spectrometry for Recovery, Detection and Sequencing of Phosphopeptides. Rapid Commun. Mass Spectrom. 2004, 18, 1721-1730.

45. Yang, X. F.; Wu, H. P.; Kobayashi, T.; Solaro, R. J.; van Breemen, R. B. Enhanced Ionization of Phosphorylated Peptides during MALDI TOF Mass Spectrometry. Anal. Chem. 2004, 76, 1532-1536.

46. Kjellstrom, S.; Jensen, O. N. Phosphoric Acid as a Matrix Additive for MALDI MS Analysis of Phosphopeptides and Phosphoproteins. Anal. Chem. 2004, 76, 5109-5117.

47. Bluhm, E. A.; Bauer, E.; Chamberlin, R. M.; Abney, K. D.; Young, J. S. Jarvinen, G. D. Surface Effects on Cation Transport across Porous Alumina Membranes. Langmuir 1999, 15, 8668-8672.

48. Parks, G. A. Isoelectric Points of Solid Oxides Solid Hydroxides and Aqueous Hydroxo Complex Systems. Chem. Rev. 1965, 65, 177-198.

49. Zhang, H. X.; Zhang, C. J.; Lajoie, G. A.; Yeung, K. K. C. Selective Sampling of Phosphopeptides for Detection by MALDI Mass Spectrometry. Anal. Chem. 2005, 77, 6078-6084. 